\title{
Thermal Inactivation Kinetics of Kudzu (Pueraria lobata) Polyphenol Oxidase and the Influence of Food Constituents
}

\author{
Junping Liu ${ }^{1}$, Jiayan Zhang ${ }^{1}$, Tao Liao ${ }^{1}$, Lei Zhou ${ }^{1}$, Liqiang Zou ${ }^{1}$, Yafei Liu ${ }^{1}$, Li Zhang ${ }^{2}$ and Wei Liu ${ }^{1,3, *}$ \\ 1 State Key Laboratory of Food Science and Technology, Nanchang University, Nanchang 330047, China; \\ ljpfood@163.com (J.L.); ncuzhangjiayan@163.com (J.Z.); 15180122056@163.com (T.L.); \\ ncuskzhoulei@163.com (L.Z.); zouliqiang2010@163.com (L.Z.); ncuspyliuyafei@163.com (Y.L.) \\ 2 Key Laboratory of Tropical Crop Products Processing of Ministry of Agriculture and Rural Affairs, \\ Agricultural Products Processing Research Institute of Chinese Academy of Tropical Agricultural Sciences, \\ Guangdong 524001, China; zhang1993123321@163.com \\ 3 National R\&D Center for Freshwater Fish Processing, Jiangxi Normal University, Nanchang 330022, China \\ * Correspondence: liuwei@ncu.edu.cn; Tel.: +86-0791-88305872 (ext. 8106)
}

Citation: Liu, J.; Zhang, J.; Liao, T.; Zhou, L.; Zou, L.; Liu, Y.; Zhang, L.; Liu, W. Thermal Inactivation Kinetics of Kudzu (Pueraria lobata) Polyphenol Oxidase and the Influence of Food Constituents. Foods 2021, 10, 1320. https://doi.org/10.3390/foods1006132

\begin{abstract}
The thermal inactivation kinetics of kudzu (Pueraria lobata) polyphenol oxidase (PPO) were investigated in model and food systems. PPO in kudzu tissue (tPPO) showed a higher thermostability than that of PPO in crude extract (cPPO) and purification fractions (pPPO). The PPO inactivation rate constant $(k)$ increased with an increase in temperature, and tPPO showed the lowest $k$ value, followed by that of $\mathrm{cPPO}$ and $\mathrm{pPPO}$ at the same temperature, indicating that PPO in the food system was more resistant to thermal treatment. Food constituents (pectin, starch, sucrose, and bovine serum albumin) in the food system decreased the activity of PPO but increased the thermostability of PPO, among which pectin exhibited the strongest protective effect against thermal inactivation, and the influence of sucrose was much slighter than that of other macromolecules. Fluorescence emission spectra indicated that $\mathrm{pPPO}$ exhibited stronger interactions with pectin than sucrose, and $\mathrm{pPPO}$ with pectin showed a more stable conformation under thermal treatment.
\end{abstract}

Keywords: polyphenol oxidase; kudzu; thermostability; thermal inactivation kinetics; food constituents; conformation

\section{Introduction}

Kudzu (Pueraria lobata) is a herbaceous, perennial plant native to East Asia and belongs to the Leguminosae family. It is a rich source of starch, dietary fiber, minerals, and isoflavonoids and possesses many nutritional and pharmacological activities [1-3], such as antioxidant, anticancer, anti-inflammation, and neuroprotective properties. Additionally, $\mathrm{kudzu}$ is used as a vegetable and edible ingredient in the preparation of various foods [4] For example, kudzu starch is used in the production of noodles, beverages, oral liquids, and various dishes, and it serves as a sauce thickener [5]. Food products containing components of kudzu have begun to attract interest from both consumers and researchers due to their health benefits. However, enzymatic browning of kudzu during storage, handling, and processing negatively affects its sensory and nutritional properties. Polyphenol oxidase (PPO) is the primary enzyme involved in enzymatic browning [6,7]. Therefore, the inactivation of PPO is important in improving the quality attributes of kudzu products.

Thermal treatment has been widely used as a non-chemical means for enzyme inactivation in food processing. The thermal inactivation of PPO from fruits and vegetables has been well evaluated in mushrooms [8,9], pear [10,11], apple [12,13], chestnut kernel [14], and pineapple [15]. The thermostability of PPO highly depended on the environmental conditions, and an obvious difference was observed in food and model systems. Purified apple PPO was almost completely inactivated after incubation at $65^{\circ} \mathrm{C}$ for $20 \mathrm{~min}$ [13], while PPO in apple slices still retained about $40 \%$ relative activity in the same condition [12]. 
Compared to crude PPO extract from pear [11], PPO in pear puree [10] showed higher thermostability at a temperature range from 30 to $100{ }^{\circ} \mathrm{C}$. The food system differs from the model system since the complex food constituents may affect the enzymatic properties during food processing [16]. The impact of pectin [17,18], protein [19,20], and sugar [21] on enzymatic properties have been investigated. However, there are few reports comparing the thermostability of PPO in food and model systems in the same study, and the effect of food constituents on the thermal inactivation kinetics remains unclear.

In this study, PPO from kudzu was purified and characterized. The thermal stability and inactivation kinetics of kudzu tissue PPO, crude PPO, and purified PPO were evaluated and compared with each other. To further illustrate the lower thermal inactivation effect in kudzu tissue, the content of food constituents, including pectin, protein, sucrose, and starch, in kudzu was analyzed, and the effect of these constituents on PPO activity, thermal inactivation kinetics, and conformation change was also evaluated.

\section{Materials and Methods}

\subsection{Materials}

Kudzu root (Pueraria lobata) was harvested from the plantation at Shangrao, Jiangxi province in eastern China, and stored at $4{ }^{\circ} \mathrm{C}$ until processing. Triton $\mathrm{X}-100$, polyvinylpolypyrrolidone (PVPP), and $m$-hydroxydiphenyl were obtained from Aladdin Chemicals Co. (Shanghai, China). Catechol was obtained from Macklin Chemicals Co. (Shanghai, China). Pectin was purchased from Sigma-Aldrich Co. (Shanghai, China). Bovine serum albumin (BSA), starch, sucrose, D-Galacturonic acid, D-Glucose ammonium sulfate, tetramethylethylenediamine (TEMED), phenylmethylsulfonyl fluoride (PMSF), SDS-PAGE loading buffer, and standard protein mixture (Marker) were purchased from Solarbio Science and Technology Co. (Beijing, China). All the other chemicals were of analytical grade. Double-distilled water was used for preparing all the solutions.

\subsection{PPO Extraction}

The extraction and purification of PPO from kudzu were carried out according to the method of Liu et al. [22] with modifications. After washing and peeling, kudzu was sliced and mashed using a blender (HX-PB1053, AUX, Zhejiang, China) with $0.1 \mathrm{M}$ phosphate buffer ( $\mathrm{pH} 6.5$ ) containing $2 \%(w / v)$ polyvinylpolypyrrolidone (PVPP), $0.5 \mathrm{M} \mathrm{NaCl}$, and $1 \%(v / v)$ triton X-100 in a proportion of 1:1 $(v / v)$ to yield puree. The mixture was stirred in an ice-water bath for $2 \mathrm{~h}$ and centrifuged (SORVALL Biofuge primo R, Thermo, Germany) for $20 \mathrm{~min}$ at $11,000 \times \mathrm{g}$ at $4{ }^{\circ} \mathrm{C}$. The supernatant was collected as the crude PPO (cPPO) and stored at $4{ }^{\circ} \mathrm{C}$ until use.

\subsection{PPO Purification}

To obtain purified PPO (pPPO), a two-step purification was conducted. Firstly, ammonium sulfate was added to cPPO, and the precipitate obtained between $20 \%$ and $30 \%$ saturation was collected by centrifugation at $11,000 \times g$ for $25 \mathrm{~min}$ at $4{ }^{\circ} \mathrm{C}$. The precipitate was dissolved in phosphate buffer ( $\mathrm{pH}$ 6.5) and dialyzed against the same buffer at $4{ }^{\circ} \mathrm{C}$ for $24 \mathrm{~h}$. Then, the dialyzed fraction was loaded onto a DEAE Sepharose fast flow column $(8 \mathrm{~cm} \times 1 \mathrm{~cm}, \mathrm{GE}$, Healthcare Bio-Sciences AB, Sweden), which was pre-equilibrated with $50 \mathrm{mM}$ phosphate buffer ( $\mathrm{pH}$ 6.5). The column was eluted with a linear gradient of sodium chloride $(0-0.5 \mathrm{M})$ in $50 \mathrm{mM}$ phosphate buffer $(\mathrm{pH} 6.5)$ at a flow rate of $0.2 \mathrm{~mL} / \mathrm{min}$. SDS-PAGE electrophoresis was performed to determine purity [23].

\subsection{Constituent Determination}

Four main constituents (pectin, protein, starch, and sucrose) in kudzu tissue, the cPPO solution, and the pPPO solution were analyzed. The content of pectin was determined by $m$ hydroxybiphenyl and expressed as galacturonic acid equivalents [22]. Protein concentration was determined by the Bradford method [24], using bovine serum albumin as standard. 
Starch and sucrose contents were determined by acid hydrolysis and expressed as reducing sugar equivalents.

\subsection{PPO Activity Assay}

PPO activity was determined based on the method of Terefe et al. [25] with slight modifications. The reaction mixture consisted of $2.7 \mathrm{~mL}$ of Mcllvaine buffer ( $\mathrm{pH} 5.0$ ), $0.2 \mathrm{~mL}$ of $0.4 \mathrm{M}$ catechol solution, and $0.1 \mathrm{~mL}$ of PPO sample. The absorbance of the assay mixture was measured at $25^{\circ} \mathrm{C}$ in the kinetic mode at $420 \mathrm{~nm}$ for $1 \mathrm{~min}$ using a UV-visible spectrophotometer (UV-1600PC, Mapada, Shanghai, China). The relative activities of PPO were calculated in accordance with Equation (1):

$$
\text { Relative activity }(\%)=\frac{\text { Activity of treated enzyme }}{\text { Activity of untreated enzyme }} \times 100 \%
$$

\subsection{Sample Preparation}

Before thermal treatment, kudzu slices $(20 \mathrm{~g})$ were vacuum packed in polyethylene bags $(5 \mathrm{~cm} \times 5 \mathrm{~cm})$, while the $\mathrm{CPPO}$ and pPPO $(0.2 \mathrm{~mL})$ samples with $2.7 \mathrm{~mL}$ of Mcllvaine buffer ( $\mathrm{pH}$ 5.0) were filled in capillary tubes ( $5 \mathrm{~mL}$ ). Samples were kept at $4{ }^{\circ} \mathrm{C}$ for $2 \mathrm{~h}$ to minimize heating lags.

The effects of food constituents on the activity of $\mathrm{pPPO}$ were examined, with pectin, BSA, starch, and sucrose in concentrations ranging from $0.5 \%$ to $3 \%(w / v)$, respectively. The resulting mixtures were labeled as "pectin-pPPO", "BSA-pPPO", "starch-pPPO", and sucrose-pPPO", respectively. They were stirred in an ice-water bath for $1 \mathrm{~h}$ and were immediately used in the experiment.

\subsection{Thermal Processing}

The thermal stability and thermal inactivation kinetics of PPO in kudzu tissue (tPPO), cPPO, pPPO, pectin-pPPO, BSA-pPPO, starch-pPPO, and sucrose-pPPO were tested according to the method of Tan et al. [26]. The thermal stability was measured by incubating samples at temperatures ranging from 45 to $90{ }^{\circ} \mathrm{C}$ at $10 \mathrm{~min}$. Thermal inactivation kinetics was carried out at temperatures ranging from 50 to $80^{\circ} \mathrm{C}$ for $0-60 \mathrm{~min}$. After thermal treatment, all samples were rapidly cooled in ice-water, then the activity of the sample was determined.

The thermal inactivation kinetics of samples was described by the first-order kinetic reaction (Equation (2)):

$$
\ln \left(A_{t} / A_{0}\right)=-k t
$$

where $A_{0}$ is the initial activity of the samples, $A_{t}$ is the residual activity after treatment time $t$ (min), and $k$ is the inactivation rate constant $\left(\mathrm{min}^{-1}\right)$.

The Arrhenius law was used to describe the temperature dependence of the $k$-values and to estimate the activation energy by linear regression analysis (Equation (3)):

$$
\ln (k)=\ln \left(k_{0}\right)-\frac{E_{a}}{R \cdot T}
$$

where $k_{0}$ is the Arrhenius constant $\left(\mathrm{min}^{-1}\right), T$ is the absolute temperature $(\mathrm{K})$, and $k$ is the inactivation rate constants at $T\left(\mathrm{~min}^{-1}\right) . E_{a}$ is the activation energy $(\mathrm{kJ} / \mathrm{mol})$, and $R$ is the universal gas constant $(8.314 \mathrm{~J} /(\mathrm{mol} \cdot \mathrm{K}))$.

The thermodynamic parameters of inactivation (change in enthalpy $(\Delta H)$, Gibbs free energy $(\Delta G)$, and entropy $(\Delta S)$ ) were determined using the equations presented below (Equations (4)-(6)):

$$
\begin{gathered}
\Delta G=-R \cdot T \cdot \ln \left(\frac{k \cdot h_{p}}{K_{B} \cdot T}\right) \\
\Delta H=E_{a}-R \cdot T
\end{gathered}
$$




$$
\Delta S=\left(\frac{\Delta H-\Delta G}{T}\right)
$$

where $R$ is the universal gas constant $(8.314 \mathrm{~J} /(\mathrm{mol} \cdot \mathrm{K})), k$ is the inactivation rate constant at $T\left(\mathrm{~s}^{-1}\right), h_{p}$ is the Planck's constant $\left(6.6262 \times 10^{-34} \mathrm{~J} \cdot \mathrm{s}\right)$, and $K_{B}$ is the Boltzmann's constant $\left(1.3806 \times 10^{-23} \mathrm{~J} / \mathrm{K}\right)$.

The half-life $\left(t_{1 / 2}\right)$ value of inactivation is given by Equation (7):

$$
t_{1 / 2}=\frac{\ln (2)}{k}
$$

The decimal reduction time ( $D$ value) is the time needed to reduce the initial activity by $90 \%$, given by Equation (8):

$$
D=\frac{\ln (10)}{k}
$$

The $Z$ value is the temperature needed to reduce the $D$ value by one log cycle (temperature sensitivity parameter), and it is obtained by plotting the $\log D$ values versus the corresponding temperatures.

\subsection{Fluorescence Spectra Analysis}

Fluorescence emission spectra of pPPO, pectin-pPPO, and sucrose-pPPO were measured using a F-4500 spectrophotometer (Hitachi, Tokyo, Japan). The details are as follows: $0.6 \mathrm{mg} / \mathrm{mL}$ pPPO was added into quartz cuvettes and treated with $0,0.2 \%, 0.4 \%, 0.6 \%$, $0.8 \%$, and $1.0 \%(w / v)$ pectin and sucrose to investigate their impact on the tertiary structure of pPPO. In addition, $\mathrm{pPPO}$, pectin (0.4\%)-pPPO, pectin (1.0\%)-pPPO, and sucrose $(1.0 \%)-\mathrm{pPPO}$ were subjected to thermal processing at $50-80{ }^{\circ} \mathrm{C}$ to further explore the effect of pectin and sucrose on the conformation change against heat. As described by Zhou et al. [27], all the samples were excited at $280 \mathrm{~nm}$ and scanned from 420 to $300 \mathrm{~nm}$ at room temperature $\left(25 \pm 1{ }^{\circ} \mathrm{C}\right)$, with the excitation and emission slit bandwidths of $5 \mathrm{~nm}$.

\subsection{Statistical Analysis}

All the experiments were performed at least in triplicate. The values are presented as means \pm standard deviation (SD). The significant differences were determined based on an analysis of variance (ANOVA) with significance at $95 \%$ confidence.

\section{Results and Discussion}

\subsection{Purification and Characterization of PPO from Kudzu}

PPO from kudzu was purified by ammonium sulfate fractionation together with DEAE Sepharose fast flow column. PPO was successfully purified 38.4-fold with $32.9 \%$ recovery following DEAE Sepharose fast flow column (Supplementary Material Table S1). After conducting the SDS-PAGE electrophoresis (Supplementary Material Figure S1), only a single prominent protein band of approximately $21 \mathrm{kDa}$ was obtained, which confirmed the effectiveness of this purification procedure. The optimum $\mathrm{pH}$ of $\mathrm{PPO}$ from kudzu ranged from 4.5 to 5.0, and the Michaelis-Menten constant $\left(K_{\mathrm{m}}\right)$ and maximum velocity $\left(V_{\max }\right)$ were estimated to be $23.54 \mathrm{mM}$ and $0.37 \Delta \mathrm{OD} / \mathrm{min}$ (catechol as substrate), respectively (Supplementary Material Figure S2). Moreover, the general constituents (starch, protein, pectin, and sucrose) in kudzu were determined. Starch showed the highest content (21.42\%) in kudzu tissue (Supplementary Material Table S2). After extraction, the cPPO solution still contained a certain amount of starch, pectin, sucrose, and protein, but starch, pectin, and sucrose were no longer detected in the $\mathrm{pPPO}$ solution and the protein concentration was significantly reduced.

\subsection{Thermal Stability of PPO}

Thermal processing from 45 to $90^{\circ} \mathrm{C}$ for $10 \mathrm{~min}$ resulted in different inactivation effects on kudzu tissue PPO (tPPO), crude PPO (cPPO), and purified PPO (pPPO) (Figure 1). 
The activity of tPPO, $\mathrm{cPPO}$, and pPPO decreased gradually with increasing processing temperatures. After $10 \mathrm{~min}$ treatment at 45 to $60^{\circ} \mathrm{C}$, only slight inactivation was found, and the activity of $\mathrm{tPPO}, \mathrm{cPPO}$, and $\mathrm{pPPO}$ remained above $80 \%$ at $60^{\circ} \mathrm{C}$, which indicated that kudzu PPO exhibited high resistance to mild thermal processing between 45 and $60^{\circ} \mathrm{C}$. With the continuous increase in temperature, $\mathrm{PPO}$ activity declined sharply, and cPPO and pPPO were completely inactivated at $85^{\circ} \mathrm{C}$, while tPPO was completely inactivated at $90^{\circ} \mathrm{C}$. Between 60 and $90^{\circ} \mathrm{C}$, pPPO showed the fastest reduction rate in activity, followed by cPPO and tPPO. After 10 min treatment at $80^{\circ} \mathrm{C}$, the residual activity of pPPO was only $11.0 \%$, whereas the values of cPPO and $\mathrm{tPPO}$ were $24.7 \%$ and $42.1 \%$, respectively. These results illustrate that $\mathrm{PPO}$ had the strongest thermostability while pPPO had the weakest. PPO in the food system displayed higher thermostability than that in the model system. This may be due to the effect of constituents in kudzu tissue.

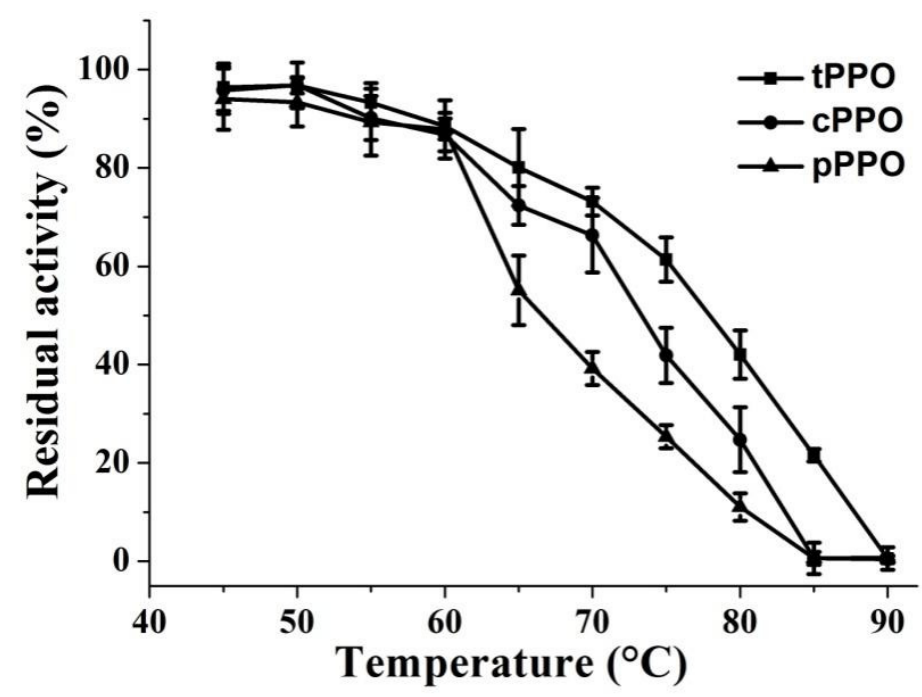

Figure 1. Thermal stability of PPO at temperatures ranging from 45 to $90{ }^{\circ} \mathrm{C}$ for $10 \mathrm{~min}$. $\mathrm{tPPO}(\boldsymbol{\square})$ : PPO in kudzu tissue. cPPO (•): PPO from the crude kudzu extract. pPPO $(\boldsymbol{\Delta})$ : purified PPO from kudzu.

In our previous studies, it was found that PPO in pear puree [10] showed higher residual activity than that of the partially purified PPO from pear [11] after thermal treatment in the temperature range of $30-100{ }^{\circ} \mathrm{C}$. The results are consistent with the viewpoint in this study that PPO in the food system was more resistant to heat, and a reasonable explanation for this could be that food constituents such as proteins and carbohydrates can protect the zymoprotein from heat [28].

\subsection{Thermal Inactivation Kinetics and Thermodynamics of PPO}

Based on the results of the thermal stability, the thermal inactivation of PPO was performed at temperatures that ranged from 50 to $80^{\circ} \mathrm{C}$ and the incubation time ranged from 0 to $60 \mathrm{~min}$ (Figure 2). Lower activity of PPO was observed in all samples as a result of a higher temperature or longer incubation time. As shown in Figure 2a, when the temperature of thermal processing was $50{ }^{\circ} \mathrm{C}$, the thermal inactivation of $\mathrm{pPPO}$ was the fastest, followed by that of $\mathrm{cPPO}$, while that of $\mathrm{tPPO}$ was the slowest. The residual activities of $\mathrm{tPPO}, \mathrm{cPPO}$, and $\mathrm{pPPO}$ were $81.8 \%, 81.6 \%$, and $74.9 \%$ after thermal processing at $50{ }^{\circ} \mathrm{C}$ for $60 \mathrm{~min}$. It could be clearly seen that the semilog relationship between the residual activity of PPO from kudzu and treatment time followed first-order kinetics well, with the correlation coefficients $\left(\mathrm{R}^{2}\right)$ ranging from 0.9708 to 0.9994 . The $k$ value of tPPO, $\mathrm{CPPO}$, and pPPO at $50^{\circ} \mathrm{C}$ increased successively and were $0.32 \times 10^{-2}, 0.36 \times 10^{-2}$, and $0.52 \times 10^{-2} \mathrm{~min}^{-1}$, respectively (Table 1 ). Similar results were observed in PPOs treated at 60,70 , and $80^{\circ} \mathrm{C}$ (Figure $2 \mathrm{~b}-\mathrm{d}$ ). With the increase in temperature, the difference during samples gradually became more obvious, and at $80^{\circ} \mathrm{C}$, the $k$ value of $\mathrm{PPO}, \mathrm{cPPO}$, and pPPO 
were $8.57 \times 10^{-2}, 14.63 \times 10^{-2}$, and $23.67 \times 10^{-2} \mathrm{~min}^{-1}$, respectively. It was observed that for $\mathrm{tPPO}, \mathrm{cPPO}$, and $\mathrm{pPPO}$, the $k$ value increased with the increase in processing temperature, indicating that kudzu PPO was more sensitive at higher temperatures. The highest $D$ value $(729.18 \mathrm{~min})$ and $t_{1 / 2}$ value $(219.50 \mathrm{~min})$ were found in $\mathrm{tPPO}$ at $50{ }^{\circ} \mathrm{C}$, which also supports the viewpoints that higher temperature leads to lower stability, and tPPO was the most stable. In comparison with cPPO from other sources, the $D$ values and $t_{1 / 2}$ values were 73.99 and $22.29 \mathrm{~min}$ for bayberry [29], 39.0 and $11.8 \mathrm{~min}$ for mushroom [8], and 17.3 and $5.2 \mathrm{~min}$ for peach [30] at $60^{\circ} \mathrm{C}$, respectively, which are lower than 158.20 and $47.62 \mathrm{~min}$ in this study, indicating that $\mathrm{PPO}$ from kudzu was more thermostable than the above-mentioned PPO. The $Z$ values of tPPO, cPPO, and $\mathrm{pPPO}$ were 21.25, 19.21, and $17.47^{\circ} \mathrm{C}$, and the corresponding $E_{a}$ were $102.68,113.67$, and $125.05 \mathrm{~kJ} / \mathrm{mol}$, respectively, the lower $Z$ value and higher $E_{a}$ suggests an increased susceptibility to heat [8].
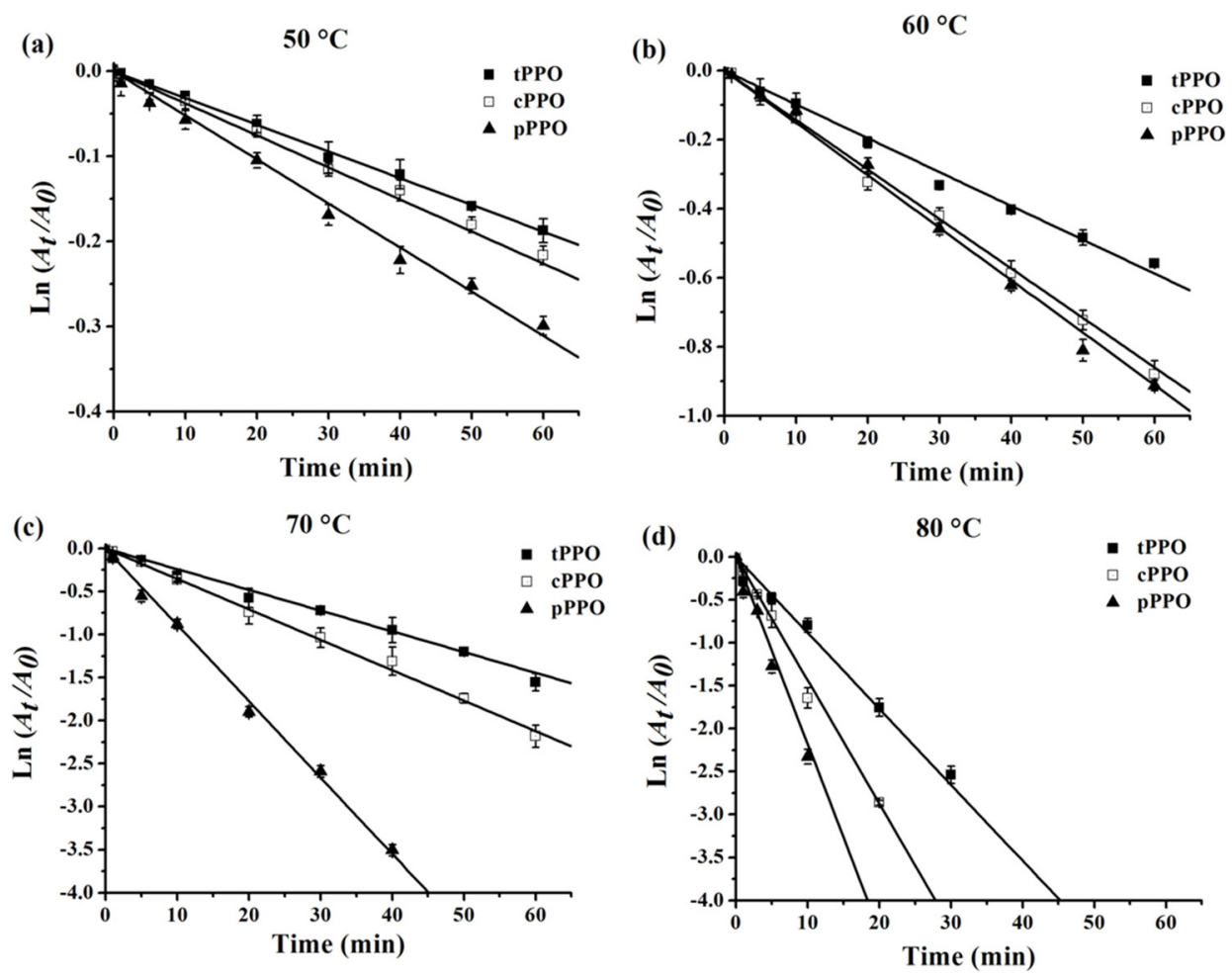

Figure 2. Thermal inactivation kinetics curves of $\mathrm{PPO}$ at $50{ }^{\circ} \mathrm{C}(\mathbf{a}), 60^{\circ} \mathrm{C}(\mathbf{b}), 70^{\circ} \mathrm{C}(\mathbf{c})$, and $80^{\circ} \mathrm{C}$ (d)

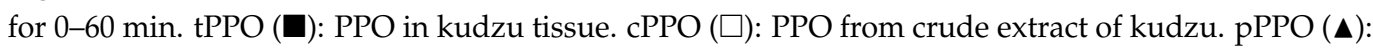
purified PPO from kudzu. 
Table 1. Thermal inactivation parameters of PPO in kudzu tissue (tPPO), crude extract (cPPO), purification fractions (pPPO), and pPPO in the presence of food constituents ${ }^{1}$.

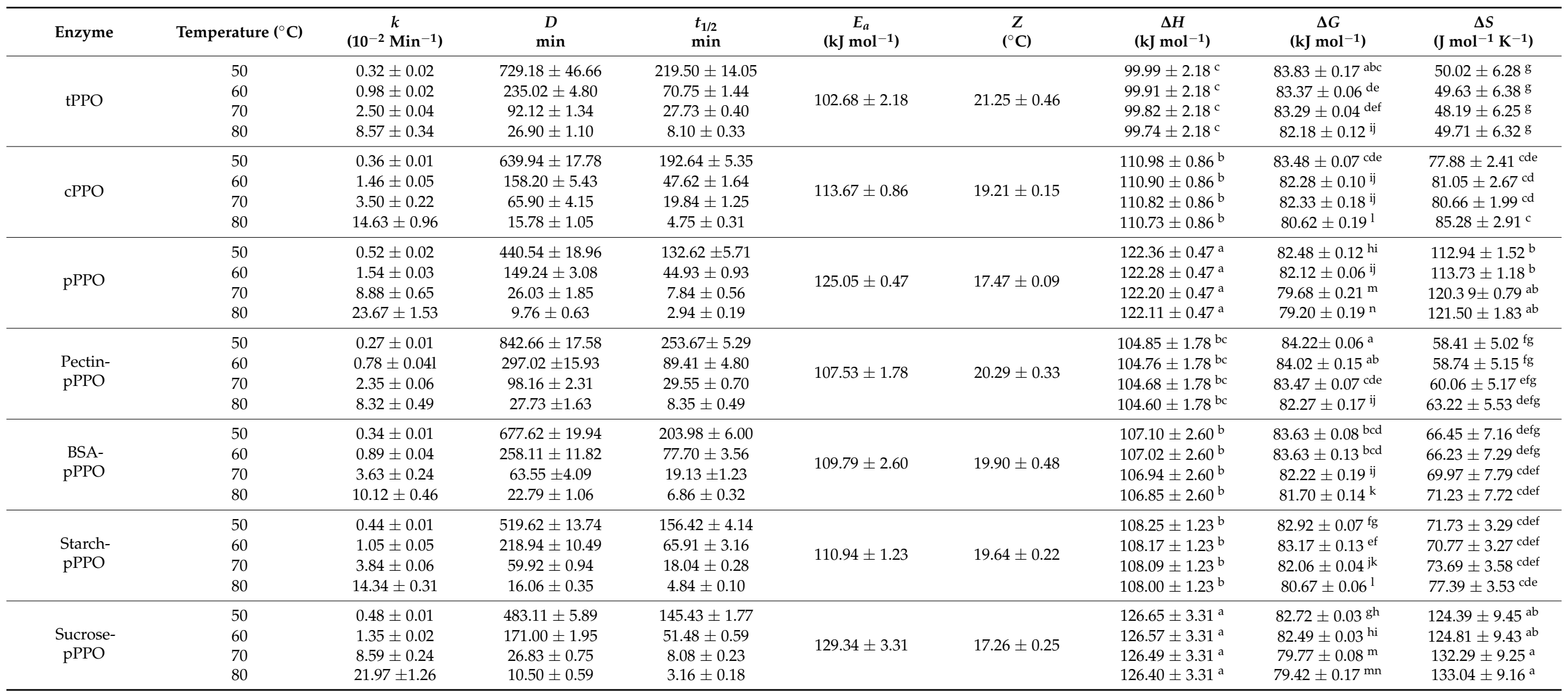

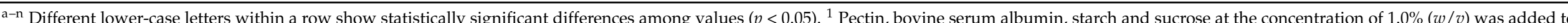

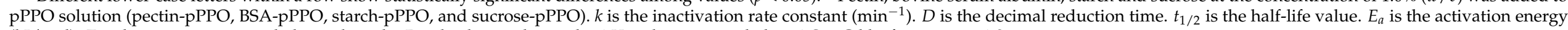
$(\mathrm{kJ} / \mathrm{mol}) . \mathrm{Z}$ is the temperature needed to reduce the $D$ value by one $\log$ cycle. $\Delta H$ is change in enthalpy. $\Delta G$ is Gibbs free energy. $\Delta S$ is entropy. 
Thermodynamic parameters provide information on the enzyme stability in the thermal inactivation process, which was helpful for evaluating the possible effects of the stabilization or destabilization of the structure of an enzyme molecule and interactions between the enzyme and media [31]. $\Delta H$ is an indicator of the number of non-covalent bonds destroyed during the inactivation process [8]. The higher $\Delta H$ value of pPPO compared with that of $\mathrm{tPPO}$ and $\mathrm{CPPO}$ at the same temperature indicates that more non-covalent bonds were broken during the formation of transition states. When increasing the processing temperature, no significant changes of $\Delta H$ were noted for the three PPO samples, which suggests that the heat capacity of PPO did not change. $\Delta G$ is another important parameter related to the stability of the enzyme; a lower $\Delta G$ represents the lower stability of the enzyme [8] and a more spontaneous inactivation reaction [31]. $\Delta S$ is a physical quantity that reflects the degree of disorder of microscopic particles in the system. From 50 to $80^{\circ} \mathrm{C}$, the $\triangle \mathrm{G}$ of $\mathrm{tPPO}, \mathrm{cPPO}$, and $\mathrm{pPPO}$ decreased, and the corresponding $\Delta S$ increased (with the exception of that of the $\mathrm{tPPO}$ at 65 and $70^{\circ} \mathrm{C}$ and that of $\mathrm{cPPO}$ at $70{ }^{\circ} \mathrm{C}$ ), which proves that the ordered structure and thermal stability of kudzu PPO decreased with the increasing temperature. Overall, the thermodynamics were closely related to the kinetics and unanimously showed that increasing the temperature led to a decrease in the stability of different PPO samples; at the same temperature, tPPO had the greatest resistance against heat followed by cPPO; pPPO was the most sensitive to heat.

These variations in inactivation kinetics and thermodynamic parameters of different PPO samples may be attributed to environmental conditions and food matrixes [26]. Ji et al. [31] observed that the $t_{1 / 2}$ value of purified $\beta$-galactosidase $(8.25$ and 0.58 min at 55 and $60{ }^{\circ} \mathrm{C}$, respectively) was significantly smaller than that of the crude enzyme (10.13 and $0.75 \mathrm{~min}$ ) in the temperature range of $55-65^{\circ} \mathrm{C}$. Furthermore, Zhou et al. [11] found that pear PPO showed higher resistance to thermal inactivation in the food systems than in model systems. Food constituents in the food system or crude extract were rich and various, which might affect the thermal inactivation of the enzyme.

\subsection{Effect of Food Constituents on the Activity of PPO}

In order to further investigate the effect of food constituents on the activity of PPO, exogenous sucrose, starch, pectin, and BSA were added to pPPO (Figure 3). The results showed that different food constituents have different effects on PPO. BSA showed the greatest impact on PPO activity: the activity of PPO was significantly decreased to $70.2 \%$ as the concentration of BSA was $1.0 \%(w / v)$, and it was only $13.6 \%$ when the concentration of BSA increased to $3.0 \%(w / v)$. Compared with BSA, the effect of sucrose, starch, and pectin on $\mathrm{pPPO}$ activity was much smaller. For sucrose, starch, and pectin, PPO activity changed slightly when the concentration of constituents was lower than $1.0 \%(w / v)$. As the concentration increased, the effects of sucrose, starch, and pectin on PPO activity became distinct. The residual activities of sucrose-pPPO, starch-pPPO, and pectin-pPPO were $90.7 \%, 82.7 \%$, and $75.1 \%$ when the additive amount reached $2.0 \%$, and $86.6 \%, 63.2 \%$, and $45.1 \%$ when the additive amount reached $3.0 \%(w / v)$. In general, all four food constituents displayed an inhibition effect on PPO activity, and BSA showed the strongest inhibition effect, followed by pectin and starch, and sucrose exhibited the weakest inhibition effect. Similarly, some previous reports studied the effects of food constituents on enzyme activity and found that different additives result in different influences on different enzymes. For instance, Isleroglu and Turker [32] reported saccharides (gum arabic and inulin) as coating materials to protect the microbial transglutaminase. Bayarri et al. [33] reported that the addition of $0-0.2 \%(w / v)$ pectin induced a decrease in lysozyme activity, and the minimum activity was found as the additive concentration of pectin reached $0.02 \%$. Chisari et al. [34] found that $72.1 \% D$-glucose and $D$-fructose treatment resulted in a decrease in the PPO activity of "Madame Moutot" strawberry fruit by $\sim 50 \%$ and $\sim 60 \%$, respectively, while the addition of $1.8 \% D$-glucose and $D$-fructose led to a slight increase in PPO activity. In this study, only the limited inhibition effect on PPO activity was observed with the addition of 
low molecular compound sucrose, while macromolecular compounds, such as BSA, pectin, and starch, showed a stronger inhibition effect on PPO.

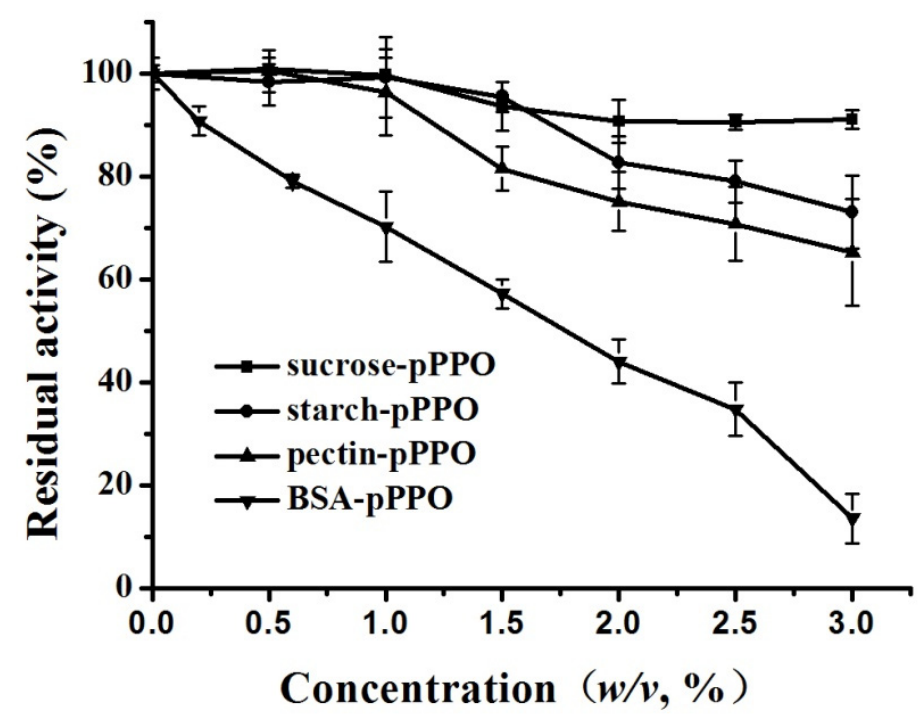

Figure 3. Effect of pectin, bovine serum albumin, starch and sucrose on the activity of purified PPO (pectin-pPPO, BSA-pPPO, starch-pPPO, and sucrose-pPPO) in concentrations ranging from $0.5 \%$ to $3 \%(w / v)$.

According to the study by Matsue and Miyawaki [35], the catalytic ability of the enzyme may be largely related to water activity and solvent ordering, and Chakraborty et al. [21] reported that sugars could change water activity, which may be a reasonable explanation for the decrease in PPO activity caused by sucrose, starch, and pectin. In addition, the abundant hydroxyl groups in starch and pectin were conducive to the formation of hydrogen bonds, which may disrupt the equilibrium of the enzyme's native structure in solvents and thus exhibit an inhibition effect [21]. Moreover, PPO can form a complex with pectin through a bridging mechanism, and the formation of electrostatic bridges may induce aggregation of PPO [36], which will hide the active site of the enzyme and lead to a lower substrate affinity and PPO activity. BSA exhibited the strongest inhibitory ability among the four food constituents. BSA molecule contains a free sulfhydryl group and 17 disulfide bonds that can be converted into sulfhydryl groups. The formed sulfhydryl groups can chelate and even remove the essential copper on the active sites of PPO, which was the factor that directly resulted in a decrease in PPO activity [37].

\subsection{Effect of Food Constituents on the Thermal Inactivation Kinetics and Thermodynamics of PPO}

Figure 4 presents the role of pectin, BSA, starch, and sucrose in the thermal inactivation of $\mathrm{pPPO}$, and the thermal inactivation of $\mathrm{pPPO}$, pectin-pPPO, BSA-pPPO, starch-pPPO, and sucrose-pPPO, fitting a linear relationship $\left(R^{2}=0.9721-0.9992\right)$. As shown in Figure 4a, pectin, $\mathrm{BSA}$, starch, and sucrose reduced the thermal inactivation rate of $\mathrm{pPPO}$, and the residual activities of pPPO, pectin-pPPO, BSA-pPPO, starch-pPPO, and sucrose-pPPO were $74.9 \%, 83.6 \%, 82.0 \%, 77.1 \%$, and $75.1 \%$, respectively, after thermal processing at $50{ }^{\circ} \mathrm{C}$ for $60 \mathrm{~min}$, and the corresponding $k$ values were $0.52 \times 10^{-2}, 0.27 \times 10^{-2}, 0.34 \times 10^{-2}$, $0.44 \times 10^{-2}$, and $0.48 \times 10^{-2} \mathrm{~min}^{-1}$, respectively (Table 1 ). Similar results are shown in Figure $4 \mathrm{~b}-\mathrm{d}$, and the corresponding $k$ values of pectin-pPPO, BSA-pPPO, starch-pPPO, and sucrose-pPPO were $0.78 \times 10^{-2}, 0.89 \times 10^{-2}, 1.05 \times 10^{-2}$, and $1.35 \times 10^{-2} \mathrm{~min}^{-1}$ at $60^{\circ} \mathrm{C}$, $2.35 \times 10^{-2}, 3.63 \times 10^{-2}, 3.84 \times 10^{-2}$ and $8.59 \times 10^{-2} \mathrm{~min}^{-1}$ at $70^{\circ} \mathrm{C}$; and $8.32 \times 10^{-2}$, $10.12 \times 10^{-2}, 14.34 \times 10^{-2}$, and $21.97 \times 10^{-2} \mathrm{~min}^{-1}$ at $80^{\circ} \mathrm{C}$, respectively. It can be noted that all four constituents exhibited protective effects on $\mathrm{PPPO}$ at all temperatures, and pectin showed the strongest protective effect, followed by BSA and starch, while sucrose showed the worst protection effect. These conclusions are also supported by gradually 
decreasing $D$ values, $t_{1 / 2}$ values, and $Z$ values and the gradually increasing $E_{a}$ in the order of pectin-pPPO, BSA-pPPO, starch-pPPO, and sucrose-pPPO. As the thermal processing temperature increased, $\Delta G$ gradually decreased, $\Delta S$ gradually increased, and $\Delta H$ did not change significantly. These changes indicated that the stability of pectin-pPPO, BSA-pPPO, starch-pPPO, and sucrose-pPPO decreased with the increase in processing temperature. These results are also consistent with the results presented in Section 3.3, wherein cPPO and $\mathrm{tPPO}$, which contain food constituents including pectin, protein, starch, and sucrose, had higher thermostability than that of pPPO. Similarly, Liu et al. [17] reported that pectin had a protective effect on the activity of peach PPO during thermal processing, and the protective effect was closely related to the concentration of pectin. Li et al. [19] found that pectin, BSA, sucrose, and trehalose could protect soluble acid invertase against HPP inactivation and the protective effect of sucrose and trehalose was weaker than that of pectin and BSA.
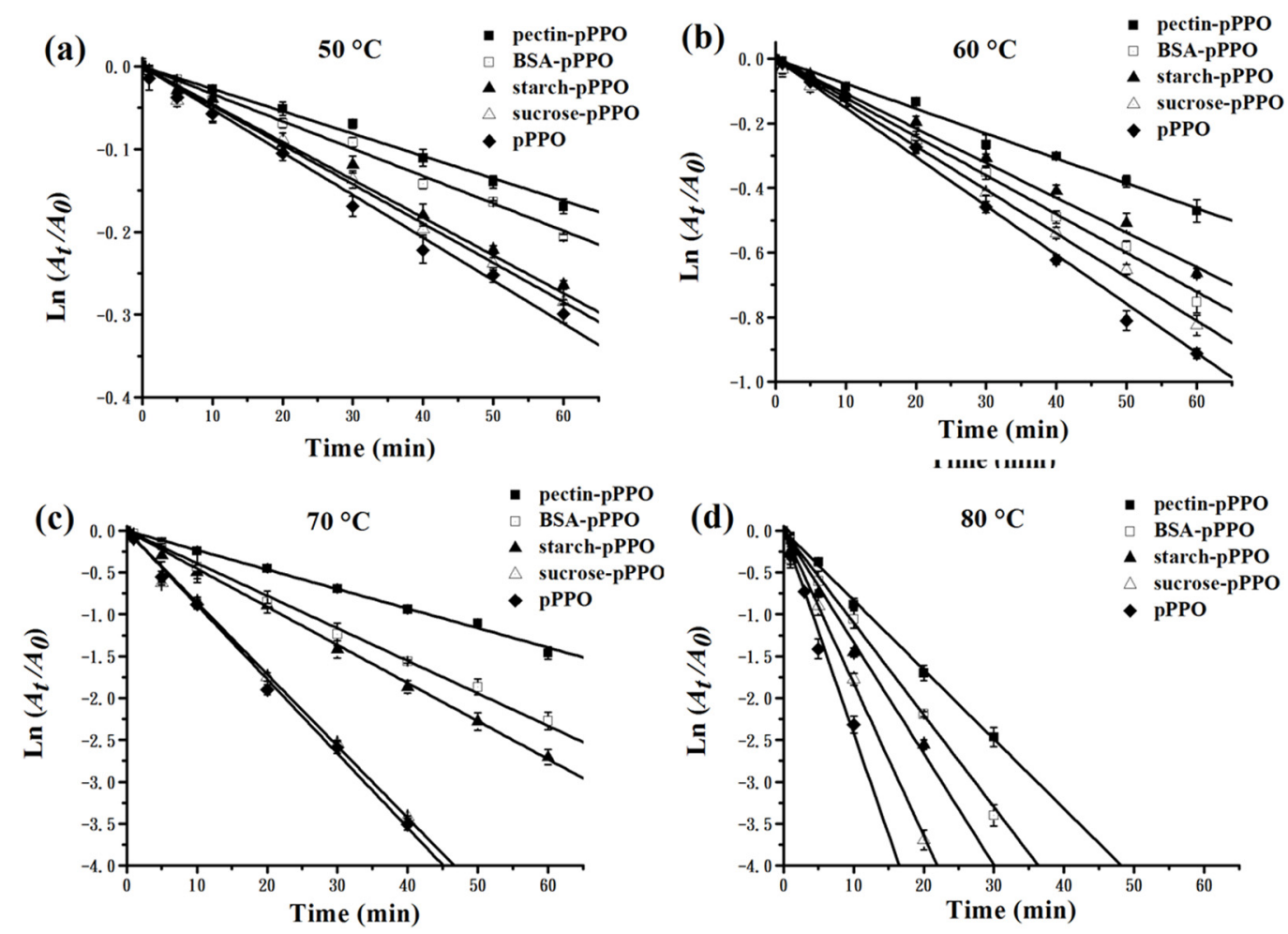

Figure 4. Thermal inactivation kinetics curves of purified PPO (pPPO) in the present of pectin (pectin-pPPO), bovine serum albumin (BSA-pPPO), starch(starch-pPPO), and sucrose (sucrose-pPPO) at a concentration of $1.0 \%(\mathrm{w} / \mathrm{v})$ at $50{ }^{\circ} \mathrm{C}(\mathbf{a}), 60^{\circ} \mathrm{C}(\mathbf{b}), 70{ }^{\circ} \mathrm{C}(\mathbf{c})$, and $80{ }^{\circ} \mathrm{C}(\mathbf{d})$ for 0-60 min.

Generally, the stability of an enzyme is affected by hydrogen bonds, hydrophobic bonds, metal bonds, ionic interactions, and disulfide bridges [38]. PPO tends to form complexes with proteins or carbohydrates, and the combination of PPO hydrophobic clusters with protein or carbohydrate molecules can shield the hydrophobic area on its surface, thereby protecting the structure of PPO from unfolding and enhancing its resistance against thermal inactivation $[17,19]$. In addition, the hydrophobic interactions and hydrogen bonds established between PPO and these food constituents, as well as the increase in solution viscosity caused by the additives, may also improve the thermal stability of PPO.

\subsection{Effect of Food Constituents on Tertiary Structure of PPO}

The effects of pectin and sucrose on PPO tertiary structure were significantly different (Figure 5). Native pPPO displayed a $340.5 \mathrm{~nm}$ peak wavelength with a corresponding fluorescence intensity of 287.6, which is similar to values of mushroom PPO reported by Zhou et al. [27]. Sucrose with a concentration of $0.2-1.0 \%(w / v)$ did not significantly change 
the shape of pPPO fluorescence spectra (Figure 5a). Meanwhile $0.4 \%, 0.6 \%, 0.8 \%$, and $1.0 \%(w / v)$ pectin caused a $0.5,1.0,1.5$, and $2.0 \mathrm{~nm}$ redshift in the peak wavelength and a $47.3 \%, 58.1 \%, 68.7 \%$, and $73.5 \%$ decrease, respectively, in the fluorescence intensity of pPPO (Figure 5b). The shape change in the fluorescence spectra was correlated with the conformational change in PPPO as well as the polarity change in the environment around tyrosine and tryptophan residues [39]. The more dramatic changes in PPPO in the presence of pectin rather than sucrose indicated that pectin had stronger interactions with $\mathrm{pPPO}$, and the driving force may be the hydrogen bond, hydrophobic interaction, and electrostatic interaction. Moreover, the reduction in the environmental $\mathrm{pH}$ and hence proton transfer induced by pectin could be another reasonable explanation, according to Li et al. [19].

(a)

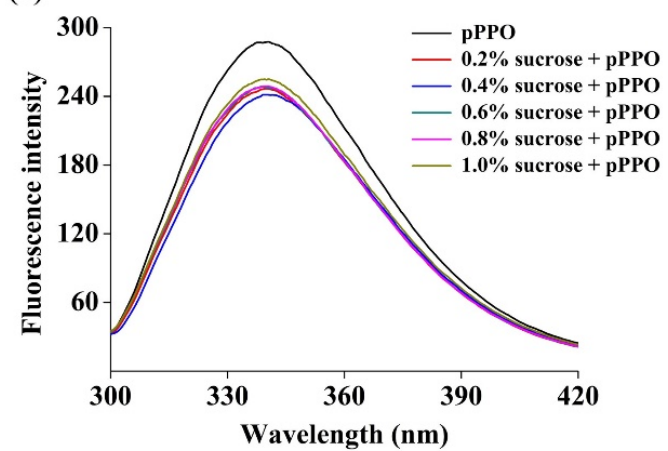

(c)

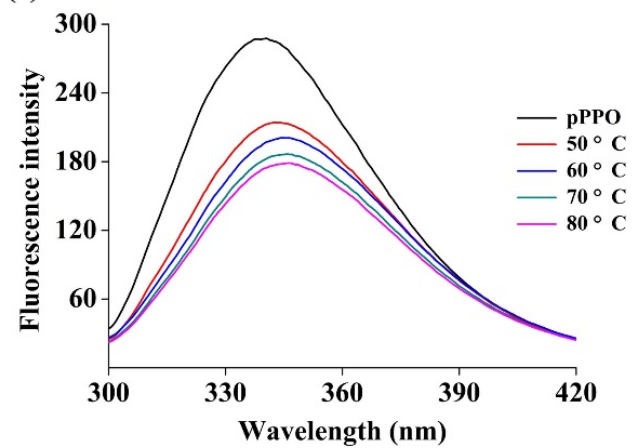

(e)

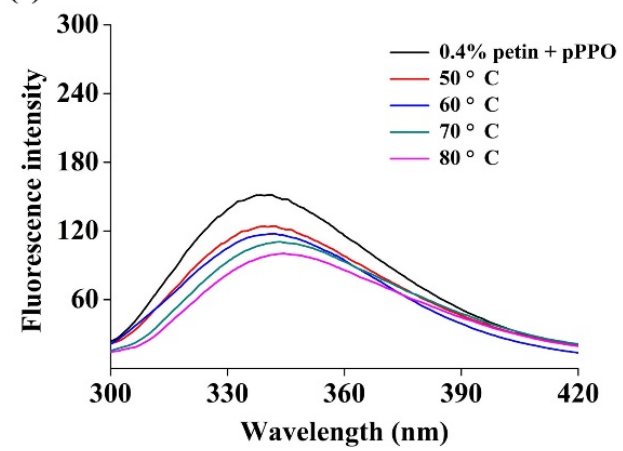

(b)

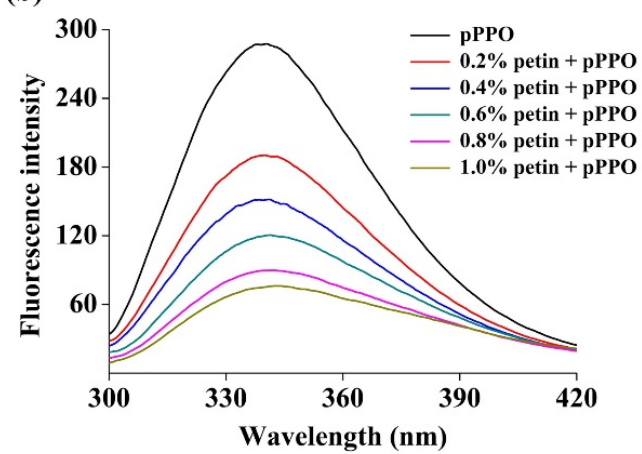

(d)

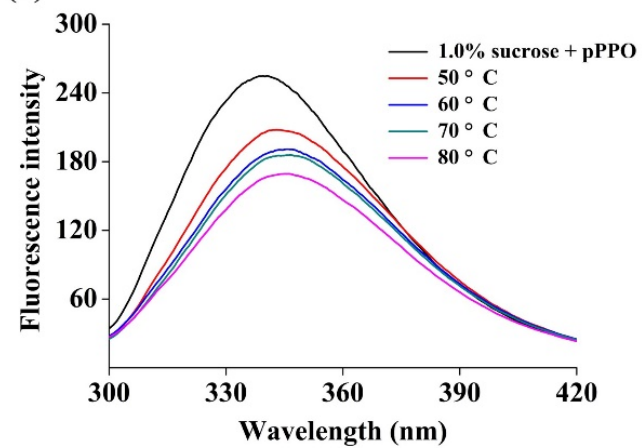

(f)

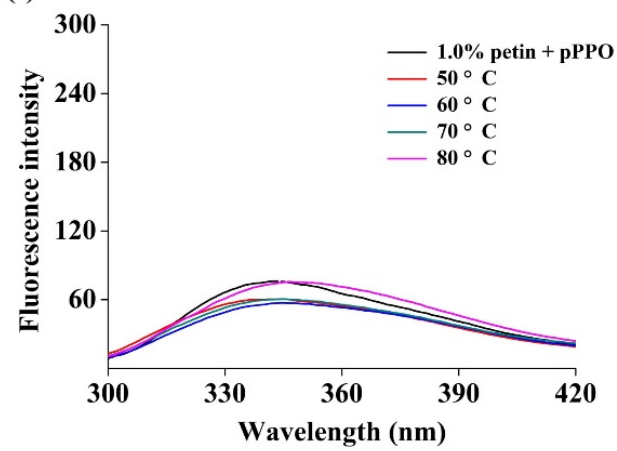

Figure 5. Fluorescence emission spectra of $\mathrm{pPPO}$ with sucrose (a) and pectin (b) at room temperature. From top to down, control sample (pPPO), pPPO with sucrose or pectin at the concentration of $0.2 \%$, $0.4 \%, 0.6 \%, 0.8 \%$, and $1.0 \%(w / v)$, respectively. Fluorescence emission spectra of pPPO (c), pPPO with sucrose $(1.0 \%)(\mathbf{d})$, pPPO with pectin $(0.4 \%)(\mathbf{e})$, and pPPO with pectin $(1.0 \%)(\mathbf{f})$ during thermal treatment from room temperature $\left(25^{\circ} \mathrm{C}\right)$ to $80^{\circ} \mathrm{C}$.

Thermal processing led to decreases in fluorescence intensity and a redshift in the peak wavelength of pPPO. The fluorescence intensities decreased to $74.5 \%, 69.9 \%, 64.8 \%$, and $62.2 \%$, with thermal processing at $50,60,70$, and $80{ }^{\circ} \mathrm{C}$, respectively, and the corresponding peak wavelengths were redshifted by $2.0,4.0,5.5$, and $6.0 \mathrm{~nm}$, respectively (Figure 5c). With 
the addition of $1.0 \%(w / v)$ sucrose, the redshifts of the pPPO fluorescence spectra were 2.5, $5.0,6.0$, and $5.5 \mathrm{~nm}$ at 50, 60, 70, and $80^{\circ} \mathrm{C}$ (Figure $5 \mathrm{~d}$ ), which are very close to the values obtained in the absence of sucrose. In comparison, the peak wavelengths of pPPO were redshifted by $1.0,1.0,2.5$, and $3.5 \mathrm{~nm}$ with $0.4 \%(w / v)$ pectin and $1.5,2.0,2.5$, and $4.0 \mathrm{~nm}$ with $1.0 \%(w / v)$ pectin at $50,60,70$, and $80^{\circ} \mathrm{C}$, respectively (Figure $5 \mathrm{e}, \mathrm{f}$ ), which are smaller than the values obtained in the case without pectin. These results illustrate that thermal processing could disrupt the tertiary structure of $\mathrm{pPPO}$; however, the presence of pectin provided protection for the $\mathrm{PPPO}$ structure against thermal processing. This supports the results presented in Section 3.5, wherein pectin provided $\mathrm{pPPO}$ with stronger protection than of sucrose at all temperatures. Heating could unfold the pPPO molecules and expose them to amino acid residues [40], which may be conducive to the association of pPPO with pectin and hence improve its structural and thermal stability.

\section{Conclusions}

In this study, kudzu (Pueraria lobata) PPO with different constituent contents was successfully obtained by different purification procedures. It was noted that the thermal stability and inactivation rate constant of $\mathrm{PPO}$ and $\mathrm{CPPO}$ containing food constituents was significantly higher than that of $\mathrm{pPPO}$, confirming that food constituents were important factors leading to the differential thermal stability of PPO in the model and food systems. Food constituents pectin, BSA, starch, and sucrose exhibited a protective effect on $\mathrm{pPPO}$ against thermal processing, and the protective effect decreased orderly. Fluorescence spectrum results demonstrated that pectin could form stronger interactions with $\mathrm{pPPO}$ than sucrose and thus improve the structural and thermal stability of pPPO. In conclusion, the enzymatic reaction of PPO in the real food system is complex. This study provides a scientific and technological basis for the further evaluation of browning control and contributes to its practical application in foods.

Supplementary Materials: The following are available online at https:/ /www.mdpi.com/article/10 .3390 / foods10061320/s1. Table S1: Purification of PPO from kudzu; Table S2: Change of constituent content in kudzu tissue, crude PPO (cPPO) solution, and purified PPO (pPPO) solution; Figure S1: SDS-PAGE electrophoresis of the purified PPO; Figure S2: Effect of pH on PPO activity (a) and Lineweaver-Burk plots of PPO (b).

Author Contributions: Conceptualization, J.L., L.Z. (Lei Zhou), and W.L.; methodology, T.L.; validation, J.L., J.Z., and Y.L.; formal analysis, J.L. and L.Z. (Lei Zhou); investigation, T.L.; resources, L.Z. (Lei Zhou), and L.Z. (Liqiang Zou).; data curation, J.L., J.Z., and Y.L.; writing-original draft preparation, J.L.; writing - review and editing, J.L. and T.L.; visualization, J.Z. and T.L.; supervision, W.L.; project administration, L.Z. (Lei Zhou); funding acquisition, J.L., L.Z. (Lei Zhou), L.Z. (Liqiang Zou), L.Z. (Li Zhang), and W.L. All authors have read and agreed to the published version of the manuscript.

Funding: This research was funded by the National Natural Science Foundation of China (grant numbers 31860452), the China Postdoctoral Science Foundation (grant numbers 2019M652288, 2020T130276), the Free exploration project of the State Key Laboratory of Food Science and Technology, Nanchang University (grant numbers SKLF-ZZB-201919), the Foundation of Key Laboratory of Tropical Crop Products Processing of Ministry of Agriculture and Rural Affairs, China (grant numbers KFKT202005), the Youth Science Foundation of Jiangxi Province (grant numbers 20181BAB214019), and the Jiangxi Province Education Department Science Foundation (grant numbers GJJ160190).

Institutional Review Board Statement: Not applicable.

Informed Consent Statement: Not applicable.

Data Availability Statement: The data presented in this study are available in this article.

Conflicts of Interest: The authors declare no conflict of interest. 


\section{References}

1. Huang, Q.; Zhang, H.; Xue, D. Enhancement of antioxidant activity of radix puerariae and red yeast rice by mixed fermentation with monascus purpureus. Food Chem. 2017, 226, 89-94. [CrossRef]

2. Wang, S.; Yang, Z.; Peng, N.; Zhou, J.; Yong, X.; Yuan, H.; Zheng, T. Optimization of ionic liquids-based microwave-assisted hydrolysis of puerarin and daidzein derivatives from radix puerariae lobatae extract. Food Chem. 2018, 256, 149-155. [CrossRef] [PubMed]

3. Liu, J.; Shi, Y.C.; Lee, D.Y. Applications of pueraria lobata in treating diabetics and reducing alcohol drinking. Chin. Herb. Med. 2019, 11, 141-149. [CrossRef]

4. Hung, P.V.; Morita, N. Chemical compositions, fine structure and physicochemical properties of kudzu (Pueraria lobata) starches from different regions. Food Chem. 2007, 105, 749-755. [CrossRef]

5. Xu, L.; Shi, W.; Cai, C.; Zhong, W.; Tu, K. Rapid and nondestructive detection of multiple adulterants in kudzu starch by near infrared (NIR) spectroscopy and chemometrics. LWT-Food Sci. Technol. 2015, 61, 590-595. [CrossRef]

6. Mayer, A.M. Polyphenol oxidases in plants and fungi: Going places? a review. Phytochemistry 2006, 67, 2318-2331. [CrossRef] [PubMed]

7. Siddiq, M.; Dolan, K.D. Characterization of polyphenol oxidase from blueberry (Vaccinium corymbosum L.). Food Chem. 2017, 218, 216-220. [CrossRef]

8. Gouzi, H.; Depagne, C.; Coradin, T. Kinetics and thermodynamics of the thermal inactivation of polyphenol oxidase in an aqueous extract from Agaricus bisporus. J. Agric. Food Chem. 2012, 60, 500-506. [CrossRef]

9. Xiong, Z.; Liu, W.; Zhou, L.; Zou, L.; Chen, J. Mushroom (Agaricus bisporus) polyphenoloxidase inhibited by apigenin: Multispectroscopic analyses and computational docking simulation. Food Chem. 2016, 203, 430-439. [CrossRef] [PubMed]

10. Zhou, L.; Liu, W.; Stockmann, R.; Terefe, N.S. Effect of citric acid and high pressure thermal processing on enzyme activity and related quality attributes of pear puree. Innov. Food Sci. Emerg. 2018, 45, 196-207. [CrossRef]

11. Zhou, L.; Liu, W.; Terefe, N.S. The inactivation kinetics of soluble and membrane-bound polyphenol oxidase in pear during thermal and high-pressure processing. Food Bioprocess Technol. 2018, 11, 1039-1049. [CrossRef]

12. Niu, S.; Xu, Z.; Fang, Y.; Zhang, L.; Yang, Y.; Liao, X.; Hu, X. Comparative study on cloudy apple juice qualities from apple slices treated by high pressure carbon dioxide and mild heat. Innov. Food Sci. Emerg. 2010, 11, 91-97. [CrossRef]

13. Han, Q.Y.; Liu, F.; Li, M.; Wang, K.L.; Ni, Y.Y. Comparison of biochemical properties of membrane-bound and soluble polyphenol oxidase from Granny Smith apple (Malus $\times$ domestica Borkh). Food Chem. 2019, 289, 657-663. [CrossRef]

14. Gong, Z.; Li, D.; Liu, C.; Cheng, A.; Wang, W. Partial purification and characterization of polyphenol oxidase and peroxidase from chestnut kernel. LWT-Food Sci. Technol. 2015, 60, 1095-1099. [CrossRef]

15. Chutintrasri, B.; Noomhorm, A. Thermal inactivation of polyphenoloxidase in pineapple puree. LWT-Food Sci. Technol. 2006, 39, 492-495. [CrossRef]

16. Zhou, L.; Liao, T.; Liu, W.; Zou, L.; Liu, C.; Terefe, N.S. Inhibitory effects of organic acids on polyphenol oxidase: From model systems to food systems. Crit. Rev. Food Sci. 2019, 6, 1-28. [CrossRef]

17. Liu, L.; Cao, S.; Yang, H.; Qi, X. Pectin plays an important role on the kinetics properties of polyphenol oxidase from honeydew peach. Food Chem. 2015, 168, 14-20. [CrossRef]

18. Ormus, S.; Oulahal, N.; Noel, C.; Degraeve, P.; Gharsallaoui, A. Effect of low methoxyl (LM) pectin complexation on the thermal and proteolytic inactivation of lysozyme: A kinetic study. Food Hydrocoll. 2015, 43, 812-818. [CrossRef]

19. Li, R.; Wang, Y.; Ling, J.; Liao, X. Effects of high pressure processing on activity and structure of soluble acid invertase in mango pulp, crude extract, purified form and model systems. Food Chem. 2017, 231, 96-104. [CrossRef]

20. Huang, N.; Cheng, X.; Hu, W.; Pan, S. Inactivation, aggregation, secondary and tertiary structural changes of germin-like protein in satsuma mandarine with high polyphenol oxidase activity induced by ultrasonic processing. Biophys. Chem. 2015, 197, 18-24. [CrossRef]

21. Chakraborty, S.; Baier, D.; Knorr, D.; Mishra, H.N. High pressure inactivation of polygalacturonase, pectinmethylesterase and polyphenoloxidase in strawberry puree mixed with sugar. Food Bioprod. Process. 2015, 95, 281-291. [CrossRef]

22. Liu, F.; Zhao, J.H.; Wen, X.; Ni, Y.Y. Purification and structural analysis of membrane-bound polyphenol oxidase from fuji apple. Food Chem. 2015, 183, 72-77. [CrossRef] [PubMed]

23. Laemli, U.K. Cleavage of structural proteins during the assembly of the head of bacteriophage T4. Nature 1970, 227, 680-685. [CrossRef]

24. Bradford, M.M. A rapid and sensitive method for the quantization of microgram quantities of prote in utilizing the principle of protein-dye binding. Anal. Biochem. 1976, 72, 248-254. [CrossRef]

25. Terefe, N.S.; Delon, A.; Buckow, R.; Versteeg, C. Blueberry polyphenol oxidase: Characterization and the kinetics of thermal and high pressure activation and inactivation. Food Chem. 2015, 188, 193-200. [CrossRef] [PubMed]

26. Tan, T.C.; Cheng, L.H.; Bhat, R.; Rusul, G.; Easa, A.M. Composition, physicochemical properties and thermal inactivation kinetics of polyphenol oxidase and peroxidase from coconut (Cocos nucifera) water obtained from immature, mature and overly-mature coconut. Food Chem. 2014, 142, 121-128. [CrossRef]

27. Zhou, L.; Liao, T.; Liu, J.P.; Zou, L.Q.; Liu, C.M.; Liu, W. Unfolding and inhibition of polyphenoloxidase induced by acidic pH and mild thermal treatment. Food Bioprocess Tech. 2019, 12, 1907-1916. [CrossRef] 
28. Terefe, N.S.; Yang, Y.H.; Knoerzer, K.; Buckow, R.; Versteeg, C. High pressure and thermal inactivation kinetics of polyphenol oxidase and peroxidase in strawberry puree. Innov. Food Sci. Emerg. 2010, 11, 52-60. [CrossRef]

29. Chourio, A.M.; Fabiola, S.F.; Zahid, M.; Martinez-Monteagudo, S.I.; Saldaña, M.D.A. Inactivation of peroxidase and polyphenoloxidase in coconut water using pressure-assisted thermal processing. Innov. Food Sci. Emerg. 2018, 49, 41-50. [CrossRef]

30. Lopes, A.M.; Toralles, R.P.; Rombaldi, C.V. Thermal inactivation of polyphenoloxidase and peroxidase in jubileu clingstone peach and yeast isolated from its spoiled puree. Food Sci. Technol. 2014, 34, 150-156. [CrossRef]

31. Ji, D.; Oey, I.; Agyei, D. Purification, characterization and thermal inactivation kinetics of $\beta$-galactosidase from Lactobacillus leichmannii 313. LWT-Food Sci. Technol. 2019, 116, 108545. [CrossRef]

32. Isleroglu, H.; Turker, I. Thermal inactivation kinetics of microencapsulated microbial transglutaminase by ultrasonic spray-freeze drying. LWT-Food Sci. Technol. 2019, 101, 653-662. [CrossRef]

33. Bayarri, M.; Oulahal, N.; Degraeve, P.; Gharsallaoui, A. Properties of lysozyme/low methoxyl (LM) pectin complexes for antimicrobial edible food packaging. J. Food Eng. 2014, 131, 18-25. [CrossRef]

34. Chisari, M.; Barbagallo, R.N.; Spagna, G. Characterization of polyphenol oxidase and peroxidase and influence on browning of cold stored strawberry fruit. J. Agric. Food Chem. 2007, 55, 3469-3476. [CrossRef] [PubMed]

35. Matsue, S.; Miyawaki, O. Influence of water activity and aqueous solvent ordering on enzyme kinetics of alcohol dehydrogenase, lysozyme, and $\beta$-galactosidase. Enzyme Microb. Technol. 2000, 26, 342-347. [CrossRef]

36. Jones, O.G.; Decker, E.A.; Mcclements, D.J. Formation of biopolymer particles by thermal treatmentof $\beta$-lactoglobulin-pectin complexes. Food Hydrocoll. 2009, 23, 1312-1321. [CrossRef]

37. Friedman, M.; Bautista, F.F. Inhibition of polyphenol oxidase by thiols in the absence and presence of potato tissue suspensions. J. Agric. Food Chem. 1995, 43, 69-76. [CrossRef]

38. Kishore, V.; Gowda, S.; Krishna, S.; Sharma, K.; Rashmi, M.; Nishita, K.P. Bovine serum albumin a potential thermostabilizer: A study on $\alpha$-amylase. J. Appl. Microbiol. 2014, 2, 37-41. [CrossRef]

39. Zhou, L.; Wu, J.; Hu, X.; Zhi, X.; Liao, X. Alterations in the activity and structure of pectin methylesterase treated by high pressure carbon dioxide. J. Agric. Food Chem. 2009, 57, 1890-1895. [CrossRef]

40. Zhou, L.; Liu, W.; Zou, L.; Xiong, Z.; Hu, X.; Chen, J. Aggregation and conformational change of mushroom (Agaricus bisporus) polyphenoloxidase subjected to thermal treatment. Food Chem. 2017, 214, 423-431. [CrossRef] 